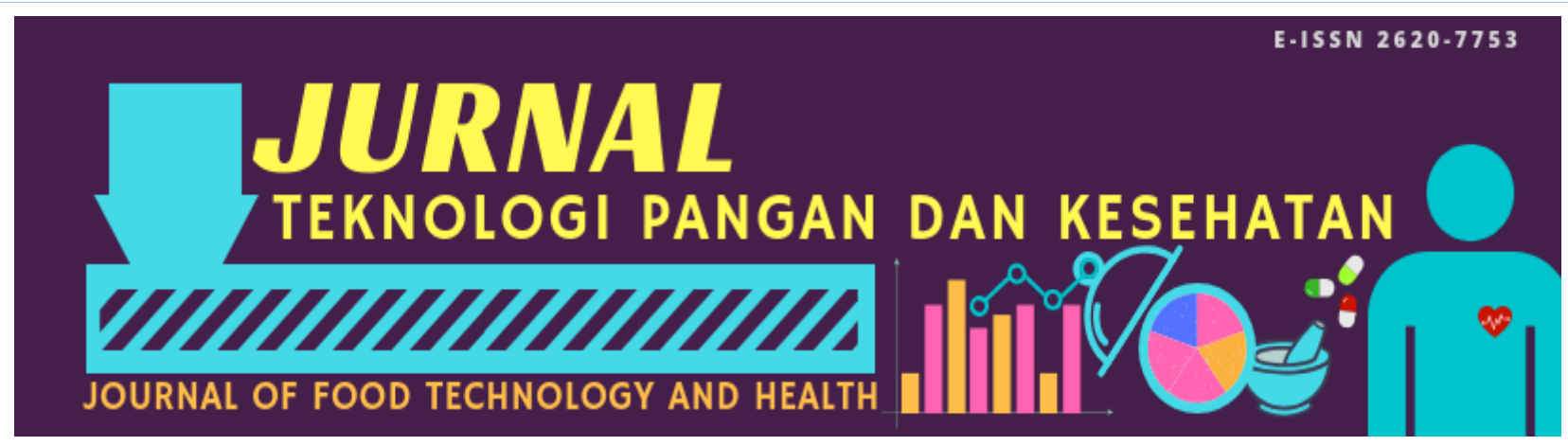

Volume I Nomor I Tahun 2019

Hasil Penelitian

Diterima 3 Jan 2019

Disetujui 28 Mei 2019

\title{
APLIKASI BIONANOKOMPOSIT PEKTIN-NANOPARTIKEL ZnO UNTUK MEMPERPANJANG UMUR SIMPAN BUAH BELIMBING (Averrhoa carambola L.)
}

\author{
Annisa Kamil ${ }^{1}$, Muhammad Fajri Romadhan ${ }^{2 *}$ \\ ${ }^{1}$ Institut Pertanian Bogor, Bogor; ${ }^{2}$ Universitas Sahid, Jakarta
}

\begin{abstract}
ABSTRAK: Belimbing (Averrhoa carambola L.) merupakan salah satu buah tropis yang mempunyai umur simpan yang pendek yaitu sekitar 2-3 hari. Masalah yang terjadi pada buah belimbing saat distribusi adalah karena faktor benturan dan penyakit yang dapat merusak buah belimbing. Tujuan dari penelitian ini adalah untuk mendapatkan konsentrasi penambahan pektin dan nanopartikel ZnO (NP-ZnO) terbaik dalam pembuatan bionanokomposit untuk mempertahankan kesegaran buah belimbing dewa sampai waktunya dikonsumsi. Nanopartikel disintesis dengan metode presipitasi pada suhu pemanasan $80^{\circ} \mathrm{C}$ selama 2 jam dan ditanur pada suhu $500^{\circ} \mathrm{C}$ selama $5 \mathrm{jam}$. Nanopartikel yang terbentuk dikarakterisasi menggunakan Fourier Transform Infra Red (FTIR) dan Scanning Electron Microscopy (SEM). Pembuatan bionanokomposit dilakukan dengan 4 taraf yaitu Pektin 1\%+ZnO 0\% (P1Z0), Pektin 1\%+ZnO 1\%(P1Z1), Pektin 1.5\%+ZnO 0\%(P1.5Z0) dan Pektin1.5\%+ZnO 1\%(P1.5Z1). Hasil analisis FTIR menunjukkan bahwa nanopartikel ZnO telah terbentuk dengan adanya puncak pada panjang gelombang $474 \mathrm{~cm}-1$ dan mempunyai morfologi bulat ketika dianalisis menggunakan SEM. Aplikasi bionanokomposit pada buah belimbing efektif dalam menurunkan susut bobot yang ditunjukkan pada perlakuan P1.5Z1 yang memiliki susut bobot paling rendah yaitu sebesar $21.42 \%$ pada hari kedelapan penyimpanan. Pada analisis kestabilan warna terlihat bahwa pada perlakuan P1.5Z0 mempunyai nilai browning indeks paling rendah yaitu 290.62 pada hari kedelapan penyimpanan. Dari penampakan fisik buah belimbing terlihat bahwa belimbing yang dilapisi dengan bionanokomposit pektin+ZnO mempunyai daya tahan terhadap penyakit yang lebih baik, terlihat dari tidak terjadi kerusakan fisik yang disebabkan oleh kapang sampai hari kedelapan penyimpanan.
\end{abstract}

Kata Kunci: buah belimbing, nanopartikel zno, bionanokomposit, umur simpan, antimikroba

ABSTRACT: Star fruit (Averrhoa carambola L.) is a tropical fruit that has a short shelf life of around 2-3 days. The problem of star fruit distribution is due to collision factors and diseases that can damage the star fruit. The purpose of this study was to obtain the best concentration of addition of pectin and ZnO nanoparticles (NP-ZnO) in the manufacture of bionanocomposite to maintain the freshness of the star fruit until the time was consumed. Nanoparticles were synthesized by precipitation method at a heating temperature of $80^{\circ} \mathrm{C}$ for 2 hours and calcinated at $500^{\circ} \mathrm{C}$ for 5 hours. The nanoparticles were characterized using Fourier Transform Infra Red (FTIR) and Scanning Electron Microscopy (SEM). The production of bionanocomposite was carried out with 4 levels namely Pectin 1\% + ZnO 0\% (P1Z0), Pectin 1\% + ZnO 1\% (P1Z1), Pectin 1.5\% + ZnO 0\% (P1.5Z0) and Pectin $1.5+$ $\mathrm{ZnO} 1 \%$ ( P1.5Z1). The results of FTIR analysis showed that ZnO nanoparticles had been formed with the presence of peaks at a wavelength of $474 \mathrm{~cm}-1$ and had spherical morphology when analyzed using SEM. Bionanocomposite application in star fruit was effective in reducing the weight loss shown in treatment P1.5Z1 which had the lowest weight loss, which was $21.42 \%$ on the eighth day of storage. From the physical appearance of star fruit it was seen that starfruit coated with bionanocomposite pectin $+\mathrm{ZnO}$ had better disease resistance, as seen from no physical damage caused by molds until the eighth day of storage.

Keywords: Star fruit, ZnO nanoparticles, bionanocomposite, shelf life, antimicrobial

\footnotetext{
*Email korespondensi:

fajriramadhan85@gmail.com
} 


\section{PENDAHULUAN}

Belimbing dewa adalah tanaman buah lokal unggulan dari kota Depok, Jawa Barat yang merupakan salah satu varietas dari belimbing manis (Averrhoa carambola L.). Sumiasih et al. (2016) menjelaskan belimbing dewa memiliki warna kuning bercampur jingga cerah, bentuk bintang yang sempurna, kulit mengkilap, renyah, mengandung banyak air (juicy) dan mempunyai rasa asam manis kaya akan vitamin A dan C dan memiliki ukuran buah yang cukup besar yaitu 150 gram - 350 gram per buah.

Badan Pusat Statistik mengeluarkan data bahwa produksi buah belimbing di daerah Depok, Jawa Barat adalah sebesar 2517,6 ton/tahun. Belimbing dewa yang siap saji memiliki masa kesegaran yang pendek yaitu 3 - 4 hari. Beberapa faktorfaktor biologis pada buah belimbing yang penting untuk dihambat sehingga memiliki kesegaran yang tahan lama adalah respirasi, produksi etilen, transpirasi, faktor morfologis, kerusakan patologis, dan kerusakan fisik.

Film bionanokomposit dapat dijadikan salah satu cara untuk mempertahankan kesegaran buah. Film ini berfungsi sebagai pengikat warna, flavor, sumber gizi, dan bahan antioksidan. Keuntungan lain yang tampak langsung dari edible film adalah peningkatan kilap buah serta memperbaiki penampilan buah sehingga lebih diterima oleh konsumen (Shahidan et al., 2011). Berbagai penelitian mengenai pelapisan pada buah menggunakan film bionanokomposit untuk mempertahankan kesegaran buah telah cukup banyak dilakukan.

Sabarisman et al., (2015) telah mengaplikasikan nanocoating yang berasal dari pektin dan nanopartikel ZnO untuk mempertahankan kesegaran salak pondoh dimana hasil pengaruh pelapisan menggunakan larutan nanokomposit terhadap buah salak pondoh yaitu mampu menekan susut bobot, menghambat pertumbuhan mikroba, dan tidak bepengaruh terhadap kenampakan visual warna kulit buah.
Dengan demikian penggunaan pektin dan naopartikel $\mathrm{ZnO}$ sebagai bionanokomposit menjadi salah satu cara alternatif untuk mempertahankan kesegaran buah belimbing dewa. Bionanokomposit pektin dengan penambahan nanopartikel ZnO berpotensi menjadikan film memiliki kemampuan antimikroba sehingga dapat digunakan dalam pengawetan buah-buahan. Berdasakan hal tersebut, penelitian ini bertujuan untuk mendapatkan konsentrasi penambahan pektin dan nanopartikel $\mathrm{ZnO}$ terbaik agar dapat mempertahankan kesegaran buah belimbing dewa sampai waktunya dikonsumsi.

\section{METODE PENELITIAN}

Bahan yang digunakan dalam penelitian ini adalah senyawa kimia $\mathrm{Zn}$ (NO3)2.4H2O (zinc nitrat) dari Merck, pektin (Indonesia), $\mathrm{NaOH}$ dari Merck, dan air demineral. Peralatan analisis yang akan digunakan adalah Fourier Transform Infra Red (FTIR) Spectroscopy Bruker untuk mengetahui finger print dari Nanopartikel ZnO. Untuk memperkirakan ukuran dan bentuk partikel yang terbentuk digunakan Scanning Electron Microscope (SEM Zeiss EVO MA10) dengan perbesaran 5.000x dengan resolusi $200 \AA ̊$ dan akselerasi tegangan sebesar $11 \mathrm{kV}$. Laboratorium yang digunakan untuk sintesis nanopartikel, pengujian antimikroba dan pengujian umur simpan buah belimbing adalah Laboratorium Teknologi Pangan USAHID Jakarta.

Penelitian ini terbagi dalam tiga tahap, yaitu sintesis NP-ZnO, pembuatan larutan bionanokomposit dan aplikasi larutan edible coating pada buah belimbing (Romadhan dan Pujilestari, 2018). Sintesis NP-ZnO mengacu pada metode yang dilakukan oleh Romadhan et al. (2016) dengan beberapa modifikasi. Sebanyak 1,3072 g seng nitrat dilarutkan dalam $500 \mathrm{ml}$ air demineral dan ditambahkan dengan larutan $\mathrm{NaOH} 4 \mathrm{M}$ hingga mencapai pH 13 dan diletakkan di atas hot plate stirrer. Sebanyak 7,5 mg Pektin ditambahkan ke dalam larutan dan dipanaskan pada suhu $80^{\circ} \mathrm{C}$ selama dua jam dan dinginkan hingga mencapai suhu ruang. Larutan diendapkan 
setelah mencapai suhu ruang dengan menggunakan sentrifugasi dengan kecepatan $3000 \mathrm{rpm}$ selama 15 menit. Endapan yang terbentuk dikeringkan pada suhu $105^{\circ} \mathrm{C}$ selama 5-6 jam. Bubuk NP-ZnO kemudian dipanaskan pada suhu $500^{\circ} \mathrm{C}$ selama 5 jam dan didinginkan hingga suhu ruang dengan desikator.

Pembuatan Bionanokomposit dimulai dari 100 mg NP-ZnO didispersikan di dalam 1 liter pelarut (air demineral) dan dihomogenisasi dengan menggunakan ultaturax selama 2 menit. Ke dalam larutan dispersi NP-ZnO, campurkan $10 \mathrm{~g}$ pektin dan diaduk hingga rata. Tambahkan $1 \mathrm{ml}$ gliserol sebagai plasticizer dan panaskan larutan pada suhu $60^{\circ} \mathrm{C}$ selama 10 menit dengan mengggunakan ultraturax. Pembuatan bionanokomposit dilakukan dengan 4 taraf yaitu Pektin $1 \%+\mathrm{ZnO} \quad 0 \% \quad(\mathrm{P} 1 \mathrm{Z} 0)$, Pektin $1 \%+\mathrm{ZnO}$ 1\%(P1Z1), Pektin 1.5\%+ZnO 0\%(P1.5Z0) dan Pektin1.5+Zn0 1\%(P1.5Z1).

Belimbing pada tingkat kematangan $80 \%$ disortasi berdasarkan ukuran dan warna yang seragam dan bebas dari serangan hama. Permukaan belimbing dicuci dengan air bersih dan disterilisasi dengan dicelupkan dalam larutan natrium bikarbonat dengan konsentrasi $0.9 \%$ selama 3 menit kemudian dikeringkan. Belimbing selanjutnya dicelupkan ke dalam larutan bionanokomposit selama 20 detik dan ditiriskan. Belimbing kontrol adalah belimbing tanpa coating. Sampel belimbing disimpan pada suhu ruang pada suhu $25^{\circ} \mathrm{C}$ dan dilakukan pengujian secara berkala.

\section{Perubahan Mutu Belimbing Susut bobot (AOAC, 1995)}

Nilai susut bobot belimbing diperoleh dengan membandingkan berat buah pada hari ke-n dengan berat awal buah. Pengukuran susut bobot belimbing dilakukan dengan menggunakan neraca analitik dan susut bobotnya dihitung dengan persamaan:

$$
W(\%)=\frac{(m i-m t)}{m i} \times 100 \%
$$

keterangan : $\mathrm{W}=$ susut bobot $(\%), \mathrm{mi}=$ masa awal (g), $\mathrm{mt}=$ masa akhir $(\mathrm{g})$

\section{Perubahan warna (CIE $\left.L^{*}, a^{*}, b^{*}\right)$}

Karakteristik warna belimbing diukur dengan menggunakan kamera digital dan kondisi pencahayaan dikontrol agar stabil dan jarak lensa kamera dengan sampel yaitu $30 \mathrm{~cm}$. Parameter warna CIE L, a dan b diperoleh dari analisis gambar menggunakan software adobe photoshop CS3. Hasil pengukuran yang didapat selanjutnya akan dikonversi kedalam nilai $\Delta \mathrm{L}^{*}, \Delta \mathrm{a}^{*}$ dan $\Delta \mathrm{b}^{*}$ untuk mendefinisikan perubahan warna yang terjadi. Notasi $\mathrm{L}^{*}$ menyatakan warna kromatik putih, abu-abu dan hitam. Notasi a* menyatakan warna kromatik campuran merah hingga merah dan notasi $b^{*}$ menyatakan warna kromatik campuran biru hingga kuning.

\section{Pengamatan fisik buah belimbing}

Buah belimbing hasil dokumentasi akan dihitung titik kerusakannya. Observasi buah belimbing dari tingkat kerusakannya apakah masih layak dikonsumsi atau tidak

\section{HASIL DAN PEMBAHASAN}

\section{Analisis Identifikasi NP ZnO dengan FTIR}

Hasil identifikasi finger print NP- $\mathrm{ZnO}$ terlihat pada Gambar 1.

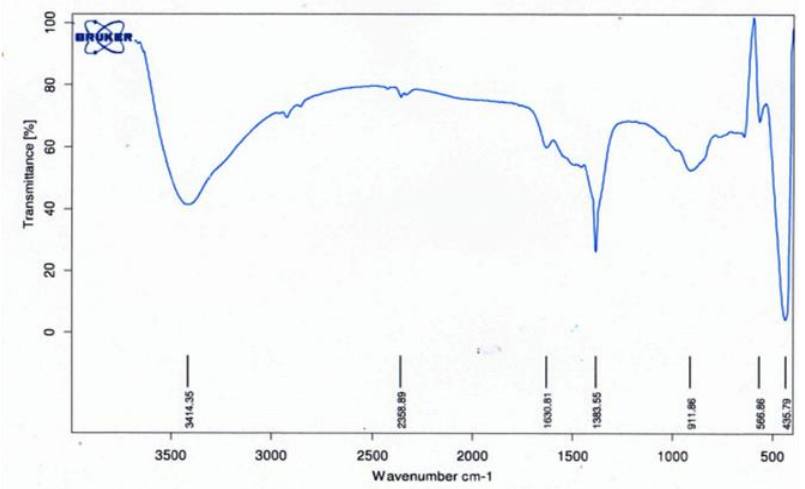

Gambar 1. Spektra FTIR nanopartikel ZnO

Wang et al. (2012) menyatakan bahwa titik serapan ikatan $\mathrm{ZnO}$ berada pada sekitar titik $474 \mathrm{~cm}^{-1}$, terlihat dari hasil pengukuran FTIR NP-ZnO terdapat puncak antara titik $435 \mathrm{~cm}^{-1}$ sampai $500 \mathrm{~cm}^{-1}$ yang menandakan bahwa nanopartikel ZnO telah terbentuk. Puncak ke $3434 \mathrm{~cm}^{-1}$ merupakan regangan vibrasi dari ikatan hidroksil $(\mathrm{O}-\mathrm{H})$ dan pada puncak ke 1384, 1466 dan 1632 cm-1 merupakan regangan vibrasi dari gugus- 
gugus karboksil (C-H) yang terikat pada permukaan partikel yang sulit untuk dihilangkan setelah proses pencucian (Bai et al. 2011).

\section{Analisis Morfologi dan ukuran Nanopartikel ZnO dengan SEM}

Untuk melihat morfologi dan ukuran NPZnO yang terbentuk, maka digunakan SEM dengan perbesaran 5.000x. Dari hasil pengamatan SEM terlihat bahwa NP ZnO dalam kondisi teragregasi, mempunyai ukuran diperkirakan kurang dari 100nm dan morfologi partikel yang bulat terlihat pada Gambar 2. Liu et al. (2012) menyatakan bahwa agregasi dapat terjadi akibat adanya penambahan capping agent pada saat proses sintesisnya.

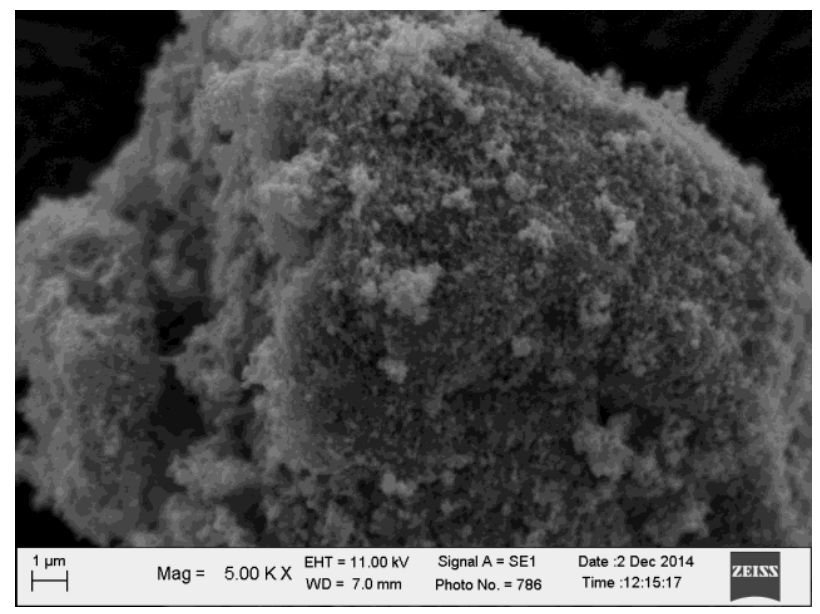

Gambar 2. Hasil analisa SEM pada nanopartikel ZnO

\section{Perubahan Mutu Buah Belimbing Susut bobot buah belimbing}

Pengukuran susut buah belimbing yang dilapisi bionanokomposit pektin-NP $\mathrm{ZnO}$ pada saat penyimpanan dapat dilihat pada Tabel 1. Dari hasil pengukuran terlihat bahwa kenaikan susut bobot dapat ditekan dengan penambahan lapisan bionanokomposit pada buah belimbing. Bionanokomposit tanpa penambahan NP-ZnO tidak memperlihatkan kemampuan untuk menahan kenaikan susut bobot, karena hanya mampu menurunkan susut bobot kurang dari 1\% dibandingkan kontrol.

Bionanokomposit yang telah ditambahkan NP-ZnO mampu menurunkan susut bobot buah belimbing yang lebih baik, dengan perlakuan terbaik yaitu pada bionanokomposit P1.5Z1, yaitu dapat menurunkan hingga $3.35 \%$ dibandingkan kontrol. Pelapis dari golongan polisakarida yang digunakan secara tunggal tidak akan memberikan pengaruh yang secara nyata untuk menurunkan susut bobot, karena banyaknya gugus hidrofilik pada bahan tersebut (Kittur et al., 2001). Dari hasil pengukuran susut bobot ini terlihat bahwa penambahan NP-ZnO dapat menahan laju penurunan susut bobot buah.

\section{Perubahan warna buah belimbing}

Seiring dengan semakin lama penyimpanan buah maka akan terjadi perubahan warna yang signifikan yaitu dari warna hijau menjadi warna jingga. Pada buah yang telah melewati fase kematangan (overripe) maka buah akan mendekati fase busuk dan akan terlihat berwarna kecoklatan. Perubahan warna pada buah pada berbagai tingkat kematangan ini dapat diukur dengan menggunakan parameter warna Hunter Lab dan Index kecoklatan (Browning Index/BI).

Pada hasil analisa warna Hunter Lab pada Tabel 2 terlihat bahwa pada perlakuan P1.5Z1 mempunyai nilai $\Delta a^{*}$ yang paling besar, hal ini menandakan bahwa buah lebih cepat menunjukkan tingkat kematangan dengan perubahan warna dari kuning menjadi jingga. Terjadi keunikan pada perubahan parameter warna $\Delta b^{*}$, di mana pada hari keenam merupakan puncak dari parameter $\Delta \mathrm{b}^{*}$ dan selanjutnya akan menurun kembali pada hari selanjutnya. Nilai $\Delta \mathrm{b}^{*} \quad$ merupakan nilai yang merepresentasikan warna kuning pada buah, sehingga puncak warna kuning terjadi pada hari keenam setelah itu buah akan berubah warna menjadi jingga sehingga nilai $\Delta \mathrm{b}^{*}$ juga akan ikut menurun dan diikuti dengan naiknya nilai $\Delta \mathrm{a}^{*}$ secara signifikan. Fluktuasi pada nilai $\Delta \mathrm{a}^{*}$ dan $\Delta \mathrm{b}^{*}$ menunjukkan perubahan warna pada tingkat kematangan yang berbeda. Buah belimbing mempunyai perubahan tingkat kematangan yang maksimal pada hari keenam dan selanjutnya akan mulai memasuki tahap overripe. 
Dengan terjadinya perubahan warna pada saat penyimpanan, maka akan meningkatkan pembentukan derajat warna coklat atau Browning index (BI) yang menunjukkan bahwa buah akan mengalami fase pembusukan. Pada Tabel 3 terlihat bahwa nilai BI yang paling tinggi adalah pada buah belimbing kontrol pada hari kedelapan, hal ini dikarenakan buah belimbing kontrol sudah mulai memasuki fase pembusukan. Dengan penambahan NP-ZnO pada bahan coating buah mangga dapat memperpanjang masa simpan buah dan mencegah terjadinya kebusukan lebih cepat.

Tabel 1. Pengukuran persen susut bobot buah belimbing

\begin{tabular}{ccccc}
\hline \multirow{2}{*}{ Perlakuan } & \multicolumn{4}{c}{ \% Susut Bobot Buah Belimbing } \\
\cline { 2 - 5 } & Hari ke-2 & Hari ke-4 & Hari ke-6 & Hari ke-8 \\
\hline kontrol & $3.38 \pm 1.18$ & $8.01 \pm 1.14$ & $18.21 \pm 2.97$ & $24.77 \pm 5.07$ \\
P1Z0 & $3.86 \pm 1.07$ & $8.16 \pm 2.15$ & $17.91 \pm 5.3$ & $24.03 \pm 7.08$ \\
P1Z1 & $3.73 \pm 0.11$ & $7.98 \pm 0.24$ & $17.55 \pm 0.22$ & $23.66 \pm 1.17$ \\
P1.5Z0 & $3.61 \pm 0.49$ & $8.14 \pm 1.52$ & $18.19 \pm 3.43$ & $24.64 \pm 4.86$ \\
P1.5Z1 & $2.78 \pm 0.30$ & $6.80 \pm 1.64$ & $15.87 \pm 3.59$ & $21.42 \pm 4.90$ \\
\hline
\end{tabular}

Tabel 2. Hasil analisa warna CIE Lab pada buah belimbing selama penyimpanan

\begin{tabular}{ccccccccccc}
\hline \multirow{2}{*}{ Hari ke- } & \multicolumn{2}{c}{ Kontrol } & \multicolumn{2}{c}{ P1Z0 } & \multicolumn{2}{c}{ P1Z1 } & \multicolumn{2}{c}{ P1.5Z0 } & \multicolumn{2}{c}{ P1.5Z1 } \\
\cline { 2 - 10 } & $\Delta \mathrm{a}^{*}$ & $\Delta \mathrm{b}^{*}$ & $\Delta \mathrm{a}^{*}$ & $\Delta \mathrm{b}^{*}$ & $\Delta \mathrm{a}^{*}$ & $\Delta \mathrm{b}^{*}$ & $\Delta \mathrm{a}^{*}$ & $\Delta \mathrm{b}^{*}$ & $\Delta \mathrm{a}^{*}$ & $\Delta \mathrm{b}^{*}$ \\
\hline 4 & 23.0 & 249.5 & 39.2 & 250.5 & 14.0 & 244.7 & 27.0 & 240.9 & 24.0 & 242.5 \\
6 & 35.3 & 250.9 & 39.3 & 251.2 & 20.7 & 255.5 & 19.2 & 244.5 & 78.9 & 247.2 \\
8 & 103.3 & 241.7 & 81.7 & 245.0 & 69.0 & 245.8 & 53.5 & 238.0 & 104.2 & 243.9 \\
\hline
\end{tabular}

Tabel 3. Hasil pengukuran Browning Index (BI) pada buah belimbing selama penyimpanan

\begin{tabular}{cccccc}
\hline Hari ke- & Kontrol & P1Z0 & P1Z1 & P1.5Z0 & P1.5Z1 \\
\hline 4 & 277.7 & 269.3 & 240.3 & 281.4 & 254.9 \\
6 & 281.3 & 277.8 & 267.5 & 277.4 & 300.3 \\
8 & 329.0 & 316.0 & 306.2 & 290.6 & 321.4 \\
\hline
\end{tabular}

\section{Penampakan fisik buah selama penyimpanan}

Selama penyimpanan 8 hari buah belimbing dapat terjadi perubahan warna dan perubahan fisik pada buah tersebut. Perubahan fisik dapat terjadi akibat perubahan fisiologis atau tingkat kematangan dan serangan penyakit akibat serangga ataupun mikroba. Pada hasil pengamatan buah belimbing terlihat bahwa pada buah kontrol hanya dapat disimpan selama 4 hari dan telah terjadi kerusakan pada hari keenam sehingga buah sudah tidak layak untuk dikonsumsi.

Pada buah yang dilapisi bionanokomposit mempunyai umur simpan yang lebih lama. Pada bionanokomposit tanpa penambahan NP-ZnO, buah dapat disimpan sampai hari keenam dan pada hari kedelapan telah terjadi kerusakan pada beberapa titik. Pada buah yang dilapisi bionanokomposit dengan penambahan NP-ZnO terlihat bahwa buah masih dalam kondisi baik pada penyimpanan hari kedelapan (Gambar 3).

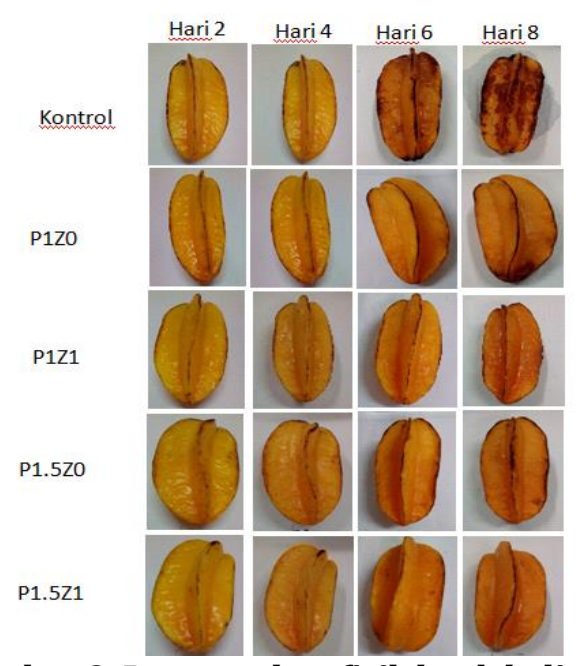

Gambar 3. Penampakan fisik buah belimbing selama penyimpanan 
Standar Nasional Indonesia (2009) tentang buah belimbing mempersyaratkan bahwa buah belimbing yang mempunyai kualitas mutu yang paling baik (super) harus bebas dari cacat kecuali cacat sangat kecil pada permukaan. Dengan pelapisan buah belimbing menggunakan bionanokomposit pektin+NP-ZnO maka kualitas buah belimbing dapat bertahan lebih lama.

Beberapa mikroba perusak buah belimbing diantaranya adalah Fusarium proliferatum yang menyebabkan penyakit brown rot disease yang menyerang peduncle dan pedicel menjadi berwarna lebih gelap (Lin et al., 2012). George et al. (2014) menjelaskan bahwa NP-ZnO mempunyai aktivitas antifungal yang dapat mencegah pertunbuhan kapang Aspergillus niger, Aspergillus flavus, Fusarium dan Cladosporium. Shao et al. (2012) melaporkan bahwa buah apel yang diberi perlakuan panas dan dilapisi kitosan dapat menunda kematangan dan mengurangi kerusakan yang disebabkan oleh kapang Penicillium expansum dan Botrytis cinerea.

Penambahan

bionanokomposit pektin+NP-ZnO dapat mencegah terjadinya kerusakan yang diakibatkan kerusakan fisiologis seperti susut bobot dan kerusakan yang disebabkan oleh serangan mikroba. Dari hasil pengamatan dalam penelitian ini terlihat bahwa buah belimbing yang dilapisi bionanokomposit pektin+NP-ZnO mempunyai pengaruh terhadap umur simpan yang lebih lama, terutama pada perlakuan P1.5Z1 yang merupakan perlakuan terbaik. Dengan penambahan bionanokomposit pektin+NP-ZnO maka dapat meningkatkan penambahan umur simpan selama 2-3 hari dibandingkan kontrol. Hasil pengamatan ini menunjukkan bahwa penambahan NP-ZnO dapat memperpanjang umur simpan dengan cara mencegah pertumbuhan mikroba perusak pada buah belimbing tersebut

\section{KESIMPULAN}

Buah belimbing dewa merupakan buah tropis yang memiliki umur simpan cukup singkat, yaitu sekitar 4-5 hari. Penambahan bionanokomposit pektin+NP-ZnO dapat meningkatkan umur simpan 2-3 hari lebih lama dibandingkan kontrol. Perlakuan terbaik dalam penelitian ini adalah pada penambahan bionanokomposit P1.5Z1 pada buah belimbing yang dapat menurunkan susut bobot $3.35 \%$ dibandingkan kontrol, Penambahan bionanokomposit P1.5Z1 juga memperlihatkan stabilitas warna yang cukup baik dan mempunyai kemampuan ketahanan penyakit yang menyebabkan kerusakan juga cukup baik sehingga dapat meningkatkan penambahan umur simpan yang cukup signifikan. Perlu dilakukannya penelitian lanjutan yang menggunakan bahan bionanokomposit selain pektin dan perlu dikembangkan rancangan penelitian menggunakan nanopartikel ZnO pada beberapa tahap konsentrasi yang berbeda.

\section{DAFTAR PUSTAKA}

AOAC., 1995. Methods of Analysis. Association of Official Analytical Chemist. Washington DC.

Bai, S., Hu, J., Li, D., Luo, R., Chen, A., \& Liu, C.C., 2011. Quantum-sized ZnO Nanoparticles: Synthesis, Characterization and Sensing Properties for $\mathrm{NO}_{2}$. Journal of Material Chemistry, 21, pp.12288-12294.

Badan Pusat Statistik (BPS). 2018. Analisis Potensi Komoditi Unggulan Hortikultura. Jawa Barat.

George, S.A., Raj, M.S., Solomon, D., \& Roselin, P., 2014. A Comparative Study of the Antifungal Activity of Zinc Oxide and Titanium Dioxide Nano and Bulk Particles with Antifungals Against Fungi Isolated From Infected Skin and Dandruff Flakes. Research and Reviews: Journal of Microbiology and Biotechnology, 3(3), pp. 23-30

Kittur, F., Saroja, N., Habibunnisa, \& Tharanathan, R., 2001. Polysaccharidebased Composite Coating Formulation for Shelf-life Extension of Fresh Banana and Mango. European Food Research and Technology, 213(4-5), pp.306-311

Liu, J., Legros, S., Ma, G., Veinot, J.G.C., von der Kammer, F., \& Hofman, T., 2012. Influence of Surface Functionalization and Particle Size on the Aggregation Kinetics of Engineered Nanoparticles. Chemosphere, 87(8), pp. 918-924 
Romadhan, M.F., Suyatma, N.E., \& Taqi, F.M., 2016. Synthesis of ZnO Nanoparticles by Precipitation Method with Their Antibacterial Effect. Indonesian Journal of Chemistry, 16(2), pp. 117-123.

Romadhan, M.F. \& Pujilestari S., 2018. Pengaruh Edible Coating Berbasis Pektin dan Kitosan yang Diinkorporasi dengan Nanopartikel ZnO terhadap Kesegaran Buah Mangga (Mangifera indica L.). Technopex Institut Teknologi Indonesia, hal. 158-166.

Sabarisman, I., Suyatma, N.E., Ahmad, U., \& Taqi, F., 2015. Aplikasi Nanocoating Berbasis Pektin dan Nanopartikel ZnO untuk Mempertahankan Kesegaran Salak Pondoh. Jurnal Mutu Pangan, 2(1), hal. 5056

Shahid, M.N. \& Nadeem, A.A., 2011. Effect of Bee Wax Coatings on Physiological Changes in Fruits of Sweet Orange CV."Blood Red". Sarhad Journal of Agriculture, 7(3), pp. 3-35.
Shao, X.F., Tu, K., Tu, S., \& Tu, J., 2012. A Combination of Heat Treatment and Chitosan Coating Delays Ripening and Reduces Decay in “Gala” Apple Fruit. Jurnal of Food Quality, 35(2).

Standar Nasional Indonesia (SNI) 4491, 2009. Belimbing. Jakarta: Badan Standarisasi Nasional.

Sumiasih, I.H., Octaviani, L., Indah, L.D., \& Yunita, E.R., 2016. Studi Perubahan Kualitas Pascapanen Buah Belimbing Dengan Beberapa Pengemasan Dan Suhu Simpan. Jurnal Agroindustri, 20(2), hal. 10-29.

Wang, Y.M., Li, J.H., \& Hong, R.Y., 2012. Large Scale Synthesis of ZnO Nanoparticle via Homogenous Precipitation. Journal of Central South University, 19, pp. 863-868. Lin, T., Zhang, C., Zhu, P., Xu, L., Nonomura, T., Matsuda, Y., \& Toyoda, H., 2012. Identification and Characterization of Brown Rot on Import Carambola Caused by Fusarium proliferatum in Shanghai. Ann. Reot. Kansai Pl. Prot., 54, pp. 61-66.

\section{BIODATA}
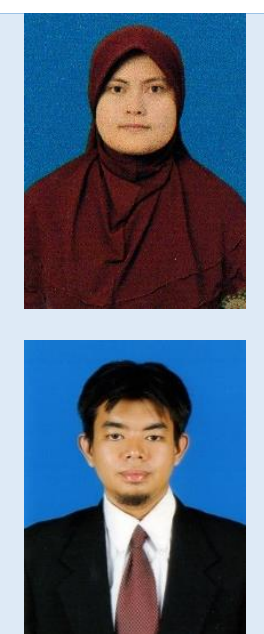

Annisa Kamil, S.TP dilahirkan pada 1 September 1989. Pada tahun 2012 menyelesaikan studi pada program studi Teknologi Hasil Pertanian di Universitas Sebelas Maret, Solo. Saat ini sedang menyelesaikan tugas akhir di pascasarjana Institut Pertanian Bogor (IPB) Jurusan Ilmu Pangan dengan judul 'Korelasi Off-Flavor dengan Morfologi Buah dari Beberapa Varietas Pepaya (Carica papaya L.)

Muhammad Fajri Romadhan adalah dosen pada Jurusan Teknologi Pangan Universitas Sahid Jakarta, dan menjadi Kepala Pusat Studi di Fakultas Teknologi Pangan Kesehatan, Universitas Sahid Jakarta. Saat ini sedang melakukan penelitian umur simpan produk-produk pertanian. Dari tahun 2015 hingga saat ini aktif menjadi auditor halal LPPOM MUI DKI Jakarta

Jurnal Teknologi Pangan dan Kesehatan (The Journal of Food Technology and Health)

Memuat artikel ilmiah berupa hasil penelitian bidang teknologi pangan dan gizi

Diterbitkan oleh Fakultas Teknologi Pangan dan Kesehatan, Universitas Sahid, Jakarta

Web: http://jurnal.usahid.ac.id/index.php/teknologi_pangan; E-mail: jtepakes@gmail.com 